\title{
Terapia Ocupacional en el posacuerdo. Retos para una profesión que se transforma
}

Sin lugar a dudas, una de las expresiones de la intensidad con que vivimos este momento los colombianos está atravesada por las emociones, inquietudes, preguntas, convicciones que nos genera la posibilidad de implementar los Acuerdos de Paz alcanzados entre el Gobierno Nacional y la hoy "Fuerza Alternativa Revolucionaria del Común" -FARC-. Este complejo escenario de posacuerdo podemos verlo como una nueva puerta de oportunidad para fortalecer nuestro actuar profesional, pensado y vinculado con los problemas sociales, económicos y culturales que afectan a grandes grupos humanos históricamente excluidos en nuestro país.

Revertir nuestras realidades marcadas por profundas inequidades e injusticias sociales requiere que nos hagamos cargo de nuestras posturas políticas y atendamos de manera renovada y creativa los desafíos que tenemos. Los retos son muchos y variados, y pueden actuarse en los escenarios institucionales, asociativos, comunitarios en los cuales participamos los terapeutas ocupacionales.

En el andamiaje institucional de los sectores de salud, educación, protección social, se necesitan transformaciones en las que podemos aportar para fortalecer las respuestas que desde allí se formulan, de manera que intencionalidades, metodologías y acciones operativas dialoguen con las necesidades de las personas y colectivos, y se tenga un real impacto en las posibilidades de mejorar condiciones de vida. La construcción de los planes de salud territorial y los planes de desarrollo territorial - PDT previstos en los acuerdos, por ejemplo, necesitan incluir nuevas visiones de salud que reconozcan las determinaciones sociales que están en la base de los procesos de salud - enfermedad. En ellos los terapeutas ocupacionales tenemos mucho que decir y aportar, por cuanto es- 
tamos involucrados en la configuración de buena parte de los haceres relacionados con esos determinantes de la salud en los que, en escenarios públicos y privados, se instalan las formas como se re-producen o se trasforman las condiciones materiales e inmateriales que hacen posible o no desarrollar el potencial humano.

Los cambios que necesitamos son de diversas escalas e involucran nuestra participación activa en la construcción de propuestas para transformar el actual sistema de seguridad social, que atraviesa una nueva crisis, por cuanto sus problemas estructurales, de organización y de financiación continúan imposibilitando que la salud sea un derecho para una gran número de colombianos. Desarrollar experiencias locales en las cuales se instalen nuevas capacidades, se recuperen los saberes de las poblaciones para cuidar la salud y se impulsen renovadas experiencias de atención primaria, se constituyen en oportunidades para que los terapeutas ocupacionales -problematizando nuestra lectura sobre la vida cotidiana y las formas como en ella trascurren diferentes temporalidades-, actuemos sobre la complejidades que enfrentamos en la actualidad para incentivar prácticas de autocuidado colectivo y de disfrute de la vida. Las apuestas por la construcción de vínculos a través de las acciones y ocupaciones colectivas se vislumbran como una posibilidad real para cimentar espacios sociales ligados a modos de vida que protejan la vida y la salud.

Aquí cobran especial atención nuestros aportes para que, por ejemplo, se reconozca cómo las prácticas de autocuidado y del cuidado del otro de hombres y mujeres concretos ayudan a satisfacer necesidades básicas de subsistencia como el alimento, el trabajo, el descanso, el ocio, el aseo, y cómo estas, ancladas a emociones y lazos, nutren vitalidades que inciden a su vez en el bienestar afectivo y emocional. Por ello, vale la pena también contribuir a nutrir desde nuestro conocimiento los debates políticos que han liderado las feministas para posicionar al cuidado como eje central del bienestar.

Ligado a ello, no es un reto menor participar de las iniciativas para pensar, construir y demandar al Estado la construcción del sistema de rehabilitación integral que no tenemos. Es un momento para reconocer que las inequidades con diferentes grupos poblacionales, incluidos quienes habitan las áreas rurales y las víctimas del conflicto armado, nos exigen construir junto a poblaciones con diversas discapacidades y a otros profesionales servicios de rehabilitación con perspectiva integral, basados en el reconocimiento de las diferencias.

Otro asunto importante se relaciona con la atención psicosocial, tanto a víctimas directas del conflicto como a otras poblaciones que de alguna manera han corporizado e incluido en sus imaginarios el miedo, la desconfianza, la desesperanza como parte de sus narrativas y pautas relacionales. Por ello, en el marco de la institucionalidad o desde las organizaciones sociales y comunitarias con las que trabajamos, necesitamos participar de la construcción de enfoques diferenciales y herramientas integrales que reparen a las víctimas sin revictimizarlas, donde despleguemos no solo acciones terapéuticas individuales que ayuden a los sujetos en 
las elaboraciones necesarias para transformar el sufrimiento emocional y potenciar los recursos internos individuales, familiares y colectivos de los cuales disponen para su recuperación; también promovamos experiencias ocupacionales colectivas que contribuyan a restaurar el tejido social, a fortalecer las identidades y a trabajar en el reconocimiento de las trayectorias vitales propias y de su lugar para resignificar las formas en las que caminamos juntos y conseguimos metas colectivas. Como terapeutas ocupacionales necesitamos ser creativos para proponer mediaciones en las que las narrativas ocupacionales, como experiencias de reflexión- acción, tejan subjetividades y formas de hacer atravesadas por la solidaridad y el bien común, constituyéndose en hechos reales de reparación integral, verdad y justicia social.

El enfoque territorial asumido en los Acuerdos nos exige como profesionales concretar lecturas integrales de las necesidades de los grupos poblacionales que pretendemos acompañar. Ampliar nuestras comprensiones sobre el territorio para asumirlo como ese espacio socialmente construido y cruzado por prácticas culturales y simbólicas permitirá ampliar nuestro horizonte de acción y ser interpelados por las experiencias de vida de las personas y grupos. Si leemos al territorio en el juego de relaciones de saber y poder en el que se mueven sus diferentes actores, nos situaremos también como sujetos políticos y actuaremos en consecuencia en un trabajo compartido de búsqueda de soluciones a problemas sociales en diversas dimensiones.

La recuperación de los saberes alrededor del hacer y sus vínculos con las construcciones de identidades en las que contribuimos los terapeutas ocupacionales nos permitirá aportar a resignificar el lugar de la cultura en las transformaciones sociales. Ello es así porque esos saberes sobre el hacer expresan también los procesos simbólicos relacionados con las producción de sentido y las formas de pensar y experimentar la vida cotidiana, y con ellos, la reproducción o transformación de la estructura social que los sostiene. Muestras claras de ello registramos cada vez más en las formas integrales y relacionales de gestionar la vida de algunos pueblos indígenas, raizales o de las negritudes, que nos retan también a re-aprender de las capacidades y experiencias de otras organizaciones, a tomar mejores decisiones sobre qué y de quiénes aprender. La mirada territorial, que nos interpela a considerar la importancia de reconocernos como sociedad pluriétnica y a validar en el trabajo la coexistencia de formas diversas y particulares de usar, apropiarse y transformar los espacios sociales, requiere también desplegar prácticas en las que contemos cómo transcurren las vidas en aquellas regiones antes nombradas solo por las acciones violentas. Los enfoques decoloniales que nos invitan a visibilizar lo que ha sido invisible, a pensar y contar de otras formas, nos animan también a hacer con ellos nuestra historia propia.

Esta demanda territorial no es una exigencia solo si trabajamos con excombatientes o con víctimas en las zonas rurales de los municipios priorizados para la inversión social, lo es también para quienes trabajamos en las ciudades. Nos es pertinente comprender lo urbano como un territorio en transformación en el que se viven tanto las consecuencias humanitarias del conflicto armado por el despla- 
zamiento forzado, como las afectaciones propias derivadas de los otros micropoderes y violencias familiares y urbanas. El crecimiento desordenado e inequitativo de las ciudades se nos muestra con rostros concretos en los que las experiencias vitales, las preguntas, sueños y apuestas por realizarse se mezclan con las implicaciones de un orden económico que incentiva el individualismo, la sobrevivencia, la marginación y el aislamiento. Por ello, en este periodo de posacuerdo trabajar en varias escalas, como lo mencionamos antes, incluye miradas interseccionales: tanto el fortalecimiento de las organizaciones sociales y la creación de experiencias de acción colectiva que reactiven la esperanza, hasta prácticas tendientes a construir una nueva institucionalidad que tenga como base la diversidad social y la participación de los sectores sociales excluidos para la construcción de ciudades equitativas.

En definitiva, esta oportunidad para repensar nuestro lugar como profesionales reafirma nuestro imperativo ético para participar de la construcción de una sociedad justa y equitativa.

Claudia Patricia Rojas Castillo ${ }^{1}$

\footnotetext{
1 Terapeuta ocupacional. Magíster en Educación. Docente Departamento de la Ocupación Humana, Universidad Nacional de Colombia. Bogotá, Colombia.cprojasc@unal.edu.co
} 